\title{
Criatividade na BNCC e em pesquisas atinentes à educação literária: indagações e desvelamentos ${ }^{1}$
}

Maria Amélia Dalvi"

\section{Resumo}

Problematiza-se o tratamento dispensado à criatividade no processo de educação escolar, focalizando-se, em seguida, as especificidades da educação literária. As fontes para a pesquisa foram a recém oficializada Base Nacional Comum Curricular e pesquisas contemporâneas desenvolvidas em programas de pós-graduação brasileiros. O que se constata, na análise do documento oficial, é a redução da criatividade a uma dimensão instrumental. Por outro lado, a análise de pesquisas contemporâneas evidencia a coexistência de distintas perspectivas no tocante ao papel da criatividade na educação literária, bem como da educação literária no desenvolvimento da criatividade. Na discussão, é retomada a proposta de superação da crença na criatividade como algo inato ou espontâneo e, na parte final, discute-se como as atuais perspectivas oficiais para o ensino de literatura na escola podem esvaziar tanto o corpo de conteúdos historicamente produzidos sobre a literatura, quanto, também, a especificidade do trabalho do professor de literatura.

Palavras-chave: Criatividade; Base Nacional Comum Curricular; Educação Literária; Ensino de Literatura.

\section{Contextualização²}

Desde meados dos anos de 1980, e mais particularmente da década de 1990 em diante, havia um sensível refluxo das correntes pedagógicas críticas, coerentemente com o momento político-econômico mundial: a ascensão de Thatcher, na Inglaterra, em 1979; de Reagan, nos EUA, em 1981; de Kohl, na Alemanha, em 1982; de Collor, no Brasil, em 1989 - que representavam a posição conservadora nos respectivos países, sob o signo do neoliberalismo/ultraliberalismo. Isso se deu, entre outros fatores, em função da ampla e sistemática disseminação, no plano ideológico, de princípios econômicos como o equilíbrio fiscal, a desregulação de mercados, a abertura das economias nacionais e a privatização dos serviços públicos. $\mathrm{O}$ vetor político necessário a

\footnotetext{
* Departamento de Linguagens, Cultura e Educação; Programa de Pós-Graduação em Letras; Programa de Pós-Graduação em Educação.
}

Data de submissão: abr. 2019 - Data de aceite: jul. 2019 http://dx.doi.org/10.5335/rdes.v15i2.9900 
uma tal reorganização do poder foi a desconfiança em relação às democracias de massa, à regulação estatal e à viabilidade de direitos amplos da cidadania assegurados ao conjunto da população em cada país (ao trabalho, à educação, à saúde, à segurança pública e à previdência social). Os efeitos desse processo (ainda) se fazem sentir no presente, em especial nos países latino-americanos (IBARRA, 2011).

O clima cultural de época ficou consignado como "pós-moderno", pois, diferentemente da condição tipicamente moderna (como conquista do mundo material), o novo momento teria seu eixo na produção de símbolos, na simulação de modelos, nos jogos de linguagem. Dunker (2018, [s. p.]) assim sintetiza o "clima" intelectual de época:

Naquela ocasião, tratava-se de entender principalmente um fenômeno estético, proeminente da arquitetura; ele se afigurava como uma desestabilização da noção de gênero e das prerrogativas canônicas do modernismo da Bauhaus e Van der Rohe. Na literatura, ele se exprimiu basicamente pela combinação de certo niilismo com a valorização de narrativas que exprimiam posições de minorias como em Paul Auster ou David Foster Wallace. Interpretado por teóricos da literatura, o fenômeno parecia ser uma nova maneira de criticar a forma romance. Lido por filósofos como Lyotard, ele descrevia um novo estilo argumentativo, marcado por narrativas comprimidas e por jogos de linguagem. Harvey e Anderson quiseram ver que tal acontecimento indicava uma nova organização do capitalismo, que precisava justificar em termos sociais a flexibilização de relações laborais, a redução dos vínculos formais e a deslocalização da produção. Guidens desdobrou o problema para a necessidade de identidades flexíveis, e Lévy trouxe a ideia de um novo tipo de organização cognitiva trazido pela disseminação da vida digital. Depois da morte do autor, delineada por Barthes nos anos 60, tínhamos nos anos 80 a morte do sujeito, como crítica das filosofias da consciência, da soberania ou da representação, que nos apresentavam, em nome deste falso universal, variações particulares de subjetividades específicas: branca, ocidental, masculina, acadêmica, economicamente privilegiada.

Neste contexto, a operacionalização e compreensão dos comportamentos, refuncionalizada, se faria não pela objetividade material e pela integração dialética entre os planos teórico e prático, mas pela produção de efeitos demonstráveis e mensuráveis, que se apresentariam, de um lado, por critérios de "performance", e, por outro, de "desempenho" e "eficácia"; assim, a legitimidade da pesquisa e do ensino se daria pelos seus "efeitos", pela "produtividade" e, enfim, pelas "competências"3 que fossem capazes de desenvolver e comprovar (GIROTTO, 2014; THIENGO, BIANCHETTI, DE MARI, 2018). Conforme Saviani (2007, p. 426-427):

Nesse novo contexto, as ideias pedagógicas sofrem grande inflexão: passa-se a assumir [...] o fracasso da escola pública, justificando sua decadência como algo inerente à incapacidade do Estado de gerir o bem comum. Com isso se advoga, também no âmbito da educação, a primazia da iniciativa privada regida pelas leis do mercado.

O descentramento e a desconstrução das ideias pedagógicas críticas de 
décadas anteriores assumem algumas estratégias ${ }^{4}$ : o uso de expressões ou termos teóricos intercambiáveis e voláteis; o agenciamento pontual de autores e tradições de pensamento com ampla aceitação científica, visando a legitimar propostas com finalidades sociais bastante diferentes; as conciliações teóricas que redundam na dificuldade de se reconhecerem as bases filosóficas das propostas educacionais; a anteposição de prefixos como "pós" ou "neo" como marcação de uma suposta superação ou uma sucessão previsível.

Toda essa "flexibilização" axiológica, epistemológica e terminológica é coerente com a reorganização das bases de produção da riqueza neste momento: substituindo o Fordismo, o Toyotismo opera com trabalhadores polivalentes visando à produção diversificada para nichos de mercado específicos. Ou seja, não se tem mais um trabalhador especializado e uma linha de produção rígida; a nova demanda é por trabalhadores polivalentes, produtivos e autorregulados:

As mudanças tecnológicas e de organização do trabalho por que passam os países de capitalismo avançado a partir dos meados da década de [19]80 configuram o mundo produtivo com algumas características tendenciais: flexibilização da produção e reestruturação das ocupações; integração de setores da produção; multifuncionalidade e polivalência dos trabalhadores; valorização dos trabalhadores não ligados ao trabalho prescrito ou ao conhecimento formalizado. (RAMOS, 2011, p. 37-38).
Para atender a esse projeto, a educação escolar proporciona um preparo básico, por meio de um currículo "enxuto", com foco no contemporâneo e no cotidiano (e, frequentemente, com valorização de práticas "espontâneas" - em geral afins à lógica da massificação cultural; e com ataques de diferentes naturezas contra o conhecimento artístico, científico e filosófico elaborado, sistematizado e formalizado).

No plano da educação literária - que é o terreno em que iremos nos situar, mais adiante -, isso é visível: nas críticas ao "excesso" de conceitos especializados, de conteúdos formalizados e de leituras demandadas pela escola; na atenção dispensada às práticas leitoras que correm à margem da educação formal, entendidas como mais "genuínas" (embora quase completamente reguladas pelas modas induzidas pela indústria da cultura) que as práticas "autoritárias" orientadas pela escola; na defesa da subjetividade e produção de leituras singulares como critério principal de validação das experiências literárias, em detrimento da importância de se conhecerem leituras críticas especializadas; na redução da importância do profissional especializado em favor de vivências mediadas por sujeitos em relações horizontalizadas, que terminam por esvaziar a função específica do professor; e, enfim, no mal-estar que causa a própria ideia de "ensino de literatura". 
A dimensão obrigatória dos currículos para a educação básica e superior contempla apenas conhecimentos gerais a respeito das diferentes áreas do conhecimento - eventualmente aprofundadas com base nos interesses e possibilidades individuais. O objetivo é oferecer fundamentos mínimos para que o sujeito se torne capaz de "aprender a aprender" por conta própria, vida afora, independentemente de se assegurarem políticas de educação escolar e de formação profissional continuada - de modo que a não-empregabilidade seja uma responsabilidade individual. Conforme Saviani (2007, p. 429):

[...] Trata-se de preparar os indivíduos para [...] se tornarem cada vez mais empregáveis, visando a escapar da condição de excluídos. [...] A pedagogia da exclusão lhes terá ensinado a introjetar a responsabilidade por essa condição. [...] Além do emprego formal, acena-se com a possibilidade de sua transformação em microempresário, com a informalidade, o trabalho por conta própria, isto é, sua conversão em empresário de si mesmo, o trabalho voluntário, terceirizado, subsumido em organizações não-governamentais etc.

Nesse contexto, termos como "criatividade", "empreendedorismo", "flexibilidade" e "inovação" recebem forte impulso, passando a ser vistos como atributos individuais desejáveis, necessários aos tempos de esfacelamento do mercado de trabalho com empregos estáveis e com direitos assegurados. A oposição a uma educação universal se apresenta com um sedutor discurso em defesa da liberdade e da autonomia, e minimiza a importância da educação escolar e do diálogo entre posições antagônicas claramente posicionadas no seio do tecido social no pleno desenvolvimento do psiquismo dos sujeitos $^{7}$. Assim, ignora-se que, para a maioria das crianças, é na escola que se tem acesso ao conhecimento humano mais elaborado, e que é a apropriação-objetivação desse conhecimento o que permitirá saltos qualitativos necessários ao desenvolvimento da consciência crítica emancipada:

[...] a consciência não pode ser identificada exclusivamente com o mundo das vivências internas, mas apreendida como ato psíquico experienciado pelo indivíduo e, ao mesmo tempo, expressão de suas relações com os outros homens e com o mundo (MARTINS, 2013, p. 29).

$\mathrm{Na}$ lógica da educação neoliberal, em vez de desenvolver a consciência crítica que supera as hegemonias momentâneas, competiria à educação escolar a responsabilidade de preparar os indivíduos para as exigências mercadológicas do momento contemporâneo, autorregulando o próprio processo (ou seja, internalizando a lógica do "aprender a aprender"). Assim, esse percurso formaria sujeitos aptos a lidar com incertezas e volatilidades no plano profissional, ao mesmo tempo em que são intensamente exigidos resultados demonstráveis e mensuráveis. 
Face à impossibilidade de abordar todos os termos-chave dessa nova lógica produtiva e educativa, abordarei, neste trabalho, diferentes modos como a criatividade comparece em documentos públicos contemporâneos (particularmente, a Base Nacional Comum Curricular) e em pesquisas dedicadas à educação literária e/ou ao ensino de literatura.

\section{Noções acerca de criatividade}

Em estudo dedicado a mapear diferentes concepções teóricas acerca da criatividade nos últimos 70 anos, Neves-Pereira (2018, p. 2) sistematiza as seguintes concepções: a) a "conceitual padrão", que congrega as noções de "novo, original e útil", em consonância com valores funcionais e pragmáticos da psicologia norte-americana, e que compreende a criatividade como um traço pessoal de personalidade e ação; b) a "conceitual-sistêmica", que não se limita à "utilidade-novidade", compreendida como algo individualmente produzido, mas que entende a criatividade como operando em um contexto social, na interação entre sujeito, cultura e campo; c) a "socio-histórica", que deriva particularmente da obra de Vygotsky $^{8}$ e colaboradores, e entende a criatividade como uma função psicológica superior (que resulta da internalização de processos intersubjetivos/ sociais), e como um processo intencionalmente desenvolvido, que inclui a brincadeira, a imaginação e a fantasia, em correlação com a apropriação-objetivação dialética dos conhecimentos historicamente produzidos, organizados e socializados pela humanidade; e d) a "sociocultural", que tem suas bases em autores díspares como Bakhtin, Dewey, Vygotsky e Valsiner; demonstra interesse especial pela criatividade cotidiana, que se constitui no dia a dia, nos pequenos atos praticados por pessoas e por grupos sociais, e entende a criatividade cotidiana como participante do mesmo continuum da criatividade "genial".

Nosso estudo se ancora em uma perspectiva materialista histórica-incompatível, portanto, com: a) o funcionalismo e pragmatismo da abordagem conceitual padrão; b) a redução da noção de contexto à lógica de um sistema fechado e unitário; c) o suposto "pluralismo" epistemológico da perspectiva identificada como "sociocultural" e com a ideia de "genialidade" individual, que se assenta, claramente, em uma base liberal. Por isso, faz-se necessário avançar um pouco mais, neste momento, na perspectiva socio-histórica da criatividade.

Como é sabido, Vygotsky e seus colaboradores (VYGOTSKY, LURIA, LEONTIEV, 2000) realizaram uma mudança significativa na compreensão do desenvolvimento humano (entendido 
agora não mais como processo evolutivo interno, mas como processo dialético sócio-histórico; não mais como pré-requisito, mas como resultado da atividade mediadora dos signos/da linguagem e das práticas sociais). Dessa feita, o sujeito criativo passou a ter uma história situada temporal, espacial e ideologicamente, que articula dialeticamente a dimensão macro à dimensão existencial particular.

Vygotsky $(2014,2018)$ propôs uma teoria da criatividade segundo a qual a imaginação criativa se desenvolve partindo da brincadeira da criança (onde a simbolização do que não existe na imediaticidade tangível da experiência sensória adquire importância fundamental para a gênese do pensamento abstrato, que será fundamental para a futura capacidade ideativa, aqui entendida como necessária à atividade criativa intencional). A brincadeira da criança, nessa perspectiva, é um ponto de partida para o processo que culminará na formação do sujeito criativo, e não a máxima realização da atividade criativa - como eventualmente o senso-comum apregoa: a criança como o ser cujo pensamento e produção seria livre das amarras sociais, e, portanto, seria plenamente criativo.

Ainda conforme o autor, um novo nível de criatividade é atingido pelo adolescente, graças à progressiva interação regulada entre imaginação/ fantasia e pensamento conceitual. E somente no adulto a criatividade se torna madura, como função mental superior que pode ser conscientemente regulada, entre outros fatores, pela incorporação e superação dos conhecimentos historicamente produzidos pela humanidade, devidamente apropriados e objetivados no curso da educação formalizada, pois

A vida reproduz sempre o velho, produz incessantemente o novo, a luta entre o velho e o novo penetra em todas as manifestações da vida (LUKÁCS, 1970, p. 203).

Ou seja: para a abordagem vygotskyana, no adulto, emoções, sentidos e cognição, devidamente situados socio-historicamente em face da apropriação e objetivação dos conhecimentos produzidos pela humanidade, são sintetizados e dão origem a uma criatividade intencional (e, portanto, não acidental):

[...] a imaginação, base de toda atividade criadora, manifesta-se, sem dúvida em todos os campos da vida cultural, tornando-se também possível a criação artística, a científica e a técnica. Nesse sentido, necessariamente, tudo o que nos cerca e foi feito pelas mãos do homem, todo o mundo da cultura, diferentemente do mundo da natureza, tudo isso é produto da imaginação e da criação humana que nela se baseia (VYGOTSKY, 2009, p. 14).

Mas, como veremos a seguir, não parece ser a compreensão majoritária. Em alentado estudo dedicado ao assunto, Saccomani (2014, p. 10-11) afirma: 
[...] tornou-se senso comum a concepção de criatividade como um potencial individual que se manifesta de modo natural ou que se desenvolve a partir de relações espontâneas com o mundo da cultura, dispensando a transmissão sistemática de conhecimento ou até mesmo a ela se contrapondo. Ademais [...] a transmissão do conhecimento é compreendida como autoritária, impositiva e repressiva, como algo que tolheria a liberdade e cercearia a criatividade dos indivíduos.

Por meio de uma alentada revisão bibliográfica sobre propostas pedagógicas para o trabalho com contos de fadas, Ferreira (2018) pontuou que a maior parte dos argumentos gravita o tema da criatividade (seu estímulo/cultivo ou seu embotamento) e, a esse respeito, chega a uma conclusão semelhante à de Saccomani (2014) - o que nos leva à constatação de pesquisadores distintos, filiados a instituições distintas, trabalhando com assuntos e recortes distintos, a partir de referenciais teóricos distintos, identificam uma hegemonia no campo especializado no tocante à criatividade.

\section{Criatividade nos documentos oficiais}

Dada a impossibilidade de abordar, neste curto estudo, todos os documentos oficiais da educação nacional que atualmente orientam o processo de escolarização obrigatória entre os 4 e os 17 anos, optamos por nos restringir ao mais recente deles: a Base Nacional Comum Curricular (BNCC).
No documento dedicado à "Etapa da Educação Infantil”, a palavra "criatividade" aparece unicamente no item "Direitos de Aprendizagem e Desenvolvimento na Educação Infantil”:

Brincar cotidianamente de diversas formas, em diferentes espaços e tempos, com diferentes parceiros (crianças e adultos), ampliando e diversificando seu acesso a produções culturais, seus conhecimentos, sua imaginação, sua criatividade, suas experiências emocionais, corporais, sensoriais, expressivas, cognitivas, sociais e relacionais (BRASIL, 2018, [s. p.], grifos nossos).

Já no documento dedicado à "Etapa do Ensino Fundamental”, não comparece nenhuma ocorrência da palavra "criatividade", nem de cognatos. Por fim, no documento dedicado à "Etapa do Ensino Médio", há algumas ocorrências.

Duas no item dedicado às "Finalidades do Ensino Médio no mundo contemporâneo":

[...] proporcionar uma cultura favorável ao desenvolvimento de atitudes, capacidades e valores que promovam o empreendedorismo (criatividade, inovação, organização, planejamento, responsabilidade, liderança, colaboração, visão de futuro, assunção de riscos, resiliência e curiosidade científica, entre outros), entendido como competência essencial ao desenvolvimento pessoal, à cidadania ativa, à inclusão social e à empregabilidade (BRASIL, 2018, [s. p.], grifos nossos).

[A preparação básica para o trabalho e a cidadania] supõe o desenvolvimento de competências que possibilitem aos estudantes inserir-se de forma ativa, crítica, criativa e responsável em um mundo do trabalho cada vez mais complexo e imprevisível, criando possibilidades para viabilizar seu projeto 
de vida e continuar aprendendo, de modo a ser capazes de se adaptar com flexibilidade a novas condições de ocupação ou aperfeiçoamento posteriores (BRASIL, 2018, [s. p.], grifos nossos).

\section{Outra ocorrência no item "As tecno-} logias digitais e a computação":

São definidas competências e habilidades, nas diferentes áreas, que permitem aos estudantes: [...] utilizar, propor e/ou implementar soluções (processos e produtos) envolvendo diferentes tecnologias, para identificar, analisar, modelar e solucionar problemas complexos em diversas áreas da vida cotidiana, explorando de forma efetiva o raciocínio lógico, o pensamento computacional, o espírito de investigação e a criatividade (BRASIL, 2018, [s. p.], grifos nossos).

Outra no item "As juventudes e o ensino médio":

Para formar esses jovens como sujeitos críticos, criativos, autônomos e responsáveis, cabe às escolas de Ensino Médio proporcionar experiências e processos que lhes garantam as aprendizagens necessárias para a leitura da realidade, o enfrentamento dos novos desafios da contemporaneidade (sociais, econômicos e ambientais) e a tomada de decisões éticas e fundamentadas. O mundo deve lhes ser apresentado como campo aberto para investigação e intervenção quanto a seus aspectos políticos, sociais, produtivos, ambientais e culturais, de modo que se sintam estimulados a equacionar e resolver questões legadas pelas gerações anteriores - e que se refletem nos contextos atuais -, abrindo-se criativamente para o novo (BRASIL, 2018, [s. p.], grifos nossos).

Outra no item "A progressão das aprendizagens essenciais do ensino fundamental para o ensino médio":
No Ensino Médio, o foco da área de Linguagens e suas Tecnologias está na ampliação da autonomia, do protagonismo e da autoria nas práticas de diferentes linguagens; na identificação e na crítica aos diferentes usos das linguagens, explicitando seu poder no estabelecimento de relações; na apreciação e na participação em diversas manifestações artísticas e culturais; e no uso criativo das diversas mídias (BRASIL, 2018, [s. p.], grifos nossos).

E uma última no item "BNCC e itinerários":

Assim, a oferta de diferentes itinerários formativos pelas escolas deve considerar $a$ realidade local, os anseios da comunidade escolar [...] de forma a propiciar aos estudantes possibilidades efetivas para construir e desenvolver seus projetos de vida e se integrar de forma consciente e autônoma na vida cidadã e no mundo do trabalho. Para tanto, os itinerários devem [...] organizar-se em torno de um ou mais dos seguintes eixos estruturantes: [...] II - processos criativos: supõem o uso e o aprofundamento do conhecimento científico na construção e criação de experimentos, modelos, protótipos para a criação de processos ou produtos que atendam a demandas para a resolução de problemas identificados na sociedade (BRASIL, 2018, [s. p.], grifos nossos).

Nota-se uma diferença na compreensão da criatividade no documento dedicado à educação infantil e ao ensino médio. No primeiro, a criatividade aparece citada no item dedicado aos direitos de aprendizagem e desenvolvimento, especificamente no item que trata da importância do "brincar cotidianamente de diversas formas, em diferentes espaços e tempos, com diferentes parceiros (crianças e adultos)". O que nos chama 
a atenção é a afirmação de que o brincar cotidianamente permitiria a ampliação e diversificação do acesso da criança às produções culturais, aos conhecimentos, à imaginação, à criatividade, às experiências. Tem-se aqui uma visão aparentemente mais próxima daquela que sistematizamos a partir de Vygotsky e colaboradores. Porém, destacamos que a criatividade (bem como a imaginação, que lhe é inerente) é listada como algo dado de antemão, algo a que as crianças teriam acesso - e não como uma função psicológica superior que deveria ser progressivamente desenvolvida.

Já no documento dedicado ao ensino médio (EM), fica bastante evidente todo o jargão neoliberal e salta aos olhos o objetivo de formar subjetividades afins à lógica produtiva em voga a partir das transformações no mundo do trabalho contemporâneo - reafirmando aquilo que discutimos na contextualização inicial deste trabalho.

Na primeira ocorrência, a criatividade aparece em parêntese explicativo, consoante às finalidades do EM, que seriam, entre outras, o "desenvolvimento de atitudes, capacidades e valores que promovam o empreendedorismo (criatividade, inovação, organização, planejamento, responsabilidade, liderança, colaboração, visão de futuro, assunção de riscos, resiliência e curiosidade científica, entre outros)". Ou seja, o foco está no desenvolvimento de "competências e habilidades" que promovam o "empreendedorismo", entendido como "essencial ao desenvolvimento pessoal, à cidadania ativa, à inclusão social e à empregabilidade". A criatividade não é abordada como capacidade imaginativa necessária ao questionamento e à transformação da sociedade, mas à sua confirmação - e, portanto, à sua reprodução.

Na segunda ocorrência, novamente, a criatividade é apresentada como uma das "competências" que possibilitam aos estudantes inserir-se no "mundo do trabalho cada vez mais complexo e imprevisível", "criando possibilidades para viabilizar seu projeto de vida e continuar aprendendo". Tudo isso na lógica de que os sujeitos sejam "capazes de se adaptar com flexibilidade a novas condições de ocupação ou aperfeiçoamento posteriores" - dimensões da nova ordem produtiva que já analisamos anteriormente.

Vê-se, nessas duas ocorrências, a hegemonia, no documento oficial, das pedagogias do "aprender a aprender" em seu atendimento à lógica econômica vigente, e em sua opção por confirmar o atual sistema produtivo.

$\mathrm{Na}$ terceira ocorrência, reitera-se a opção pela "pedagogia das competências", quando se afirma que é um dos objetivos do EM o desenvolvimento de "competências e habilidades que permitem aos estudantes: [...] utilizar, propor e/ou implementar soluções [...] para identificar, analisar, modelar e solucionar 
problemas complexos em diversas áreas da vida cotidiana, explorando de forma efetiva o raciocínio lógico, o pensamento computacional, o espírito de investigação e a criatividade". Ou seja: a criatividade (ao lado do raciocínio lógico, do pensamento computacional e do espírito investigativo) estaria dedicada a identificar, analisar, modelar e solucionar problemas da vida cotidiana. Como se pensar em uma educação literária plena, quando os usos previstos para a criatividade estão restritos aos problemas da vida cotidiana? Como a potência questionadora e revolucionária da imaginação poderia ter lugar nessa compreensão reducionista da criatividade humana?

A quarta ocorrência é a única, no documento, que evidencia uma compreensão da criatividade como desdobramento do processo de aprendizagem, pois explica que

[...] cabe às escolas de Ensino Médio proporcionar experiências e processos que lhes [aos jovens] garantam as aprendizagens necessárias para a leitura da realidade, o enfrentamento dos novos desafios [...] a tomada de decisões éticas e fundamentadas de problemas identificados na sociedade (BRASIL, 2018, [s. p.]).

Neste trecho, o documento afirma, ainda, que "O mundo deve lhes ser apresentado como campo aberto para investigação e intervenção". Porém, no final do trecho, o entendimento a respeito da criatividade afina-se novamente à lógica de formação de subjetividades que se adaptem e que sejam flexíveis, pois prevê que os jovens sejam "estimulados a equacionar e resolver questões [...], abrindo-se criativamente para o novo" (grifos meus). Ou seja, não pensando criativamente o novo, não questionando criativamente $o$ novo, não transformando criativamente o novo, mas "abrindo-se criativamente" para ele. É a mesma lógica que preside a ideia de que a criatividade deva comparecer "no uso criativo das diversas mídias".

As últimas ocorrências acontecem na explicitação das bases da proposta de "itinerários formativos”, presente na BNCC. A lógica dos itinerários formativos é afim à proposta de redução do currículo a um mínimo comum e à diversificação de percursos, baseados nos interesses e possibilidades individuais (aspecto que já discutimos no início deste trabalho). Essa lógica fica evidente na afirmação de que "a oferta de diferentes itinerários formativos pelas escolas deve considerar a realidade local, os anseios da comunidade escolar" e de que a escolarização deve "propiciar aos estudantes possibilidades efetivas para construir e desenvolver seus projetos de vida e se integrar de forma consciente e autônoma na vida cidadã e no mundo do trabalho". Mais uma vez, a perspectiva é de responsabilização do sujeito e de integração.

Ao apresentar os eixos estruturantes dos "itinerários", o documento oficial defende que entre eles devem constar os "processos criativos". Tais processos, 
segundo ainda o documento, "supõem o uso e o aprofundamento do conhecimento científico na construção e criação de experimentos, modelos, protótipos" - o que parece afim à compreensão de criatividade que vínhamos defendendo, em consonância com a perspectiva histórico-cultural. Porém, o documento prossegue, esclarecendo que esse uso e aprofundamento do conhecimento serão "para a criação de processos ou produtos que atendam a demandas para a resolução de problemas identificados na sociedade". Ou seja: a criatividade, mais uma vez, direcionada a finalidades pragmáticas, imediatistas; noutras palavras, entendida como presente apenas quando se demonstra por meio de resultados mensuráveis, controláveis, a saber, na "criação de processos e produtos que atendam a demandas".

Face à análise crítica das ocorrências do termo "criatividade" e seus cognatos na BNCC, parece bastante pertinente concluir que as propostas oficiais hegemônicas atuais no campo educacional brasileiro visam à confirmação dos elementos que discutimos na parte inicial deste trabalho.

\section{Criatividade em pesquisas contemporâneas}

Para não ficarmos restritos aos documentos oficiais, lançamo-nos à investigação sobre as ocorrências do termo "criati- vidade" em resumos de dissertações e teses defendidas no Brasil (nos programas de pós-graduação em Educação, Ensino, Letras e Linguística), no ano de 2018 (mesmo ano de promulgação da BNCC), a partir do Banco de Teses e Dissertações da Coordenação de Aperfeiçoamento de Pessoal de Nível Superior (Capes).

Ao proceder um levantamento combinado utilizando os termos-chave "criatividade" e "literatura" e os critérios explicitados no parágrafo anterior, encontramos 115 trabalhos, que foram filtrados a partir da leitura de títulos e resumos. Dados os limites deste trabalho, optamos por demonstrar, a partir de poucos exemplos, que o entendimento de parte da comunidade científica em relação à criatividade não opera uma crítica consistente daquele ideário que encontramos no documento oficial analisado acima, havendo modalidades de afinamento que vão da adesão plena, passando pela conciliação e pelo alheamento. Optamos por trazer trabalhos de distintas regiões do país (respectivamente, Norte, Sul e Nordeste).

No resumo do trabalho de Ferreira (2018), intitulado "O conto de fadas na literatura: articulando práticas de leitura no $7^{\circ}$ ano do ensino fundamental", defendido na Universidade Federal do Sul e Sudeste do Pará (UNIFESSPA), lemos que: 
Em um mundo que se mostra em constante evolução tecnológica, os meios de ensino se tornaram obsoletos, o que aumentou o desinteresse dos alunos. Assim, o uso das novas tecnologias se tornou um aliado para a modernização do meio escolar, entretanto, alguns profissionais ainda não utilizam estes recursos, muitas vezes por falta de material ou mesmo por falta de interesse do próprio professor que ainda está preso às formas tradicionais de ensino. O presente trabalho visa pensar o valor dos contos de fadas [...]. Além disso, busca envolver os discentes, utilizando não só a releitura dos contos clássicos Disney bem como dos contos originais e as suas versões cinematográficas modernas [...] contribuindo com o estímulo à leitura por fruição, até a pretensão de promover os cânones e a produção de textos do aluno, dispondo de sua criatividade (grifos nossos).

Como se vê, nesse resumo: a) os meios de ensino são vistos como obsoletos e responsáveis pelo desinteresse dos estudantes - sem qualquer problematização sobre a vida social externa à escola: o desinteresse é restrito a um problema metodológico; b) muitos profissionais não usam as novas tecnologias por desinteresse e por uma condição de prisioneiros das formas tradicionais - ou seja, por sua indisposição em se "adaptarem" ou "ajustarem" aos novos tempos; e c) a criatividade é algo de que se "dispõe" - e não algo que, intencionalmente, se aprende, se desenvolve.

Um segundo estudo, de Valcanover (2018), intitulado "Trabalha e teima, e lima, e sofre, e sua: letramento literário no ensino fundamental", defendido na Universidade Federal do Paraná (UFPR), em seu resumo, pontua que:
Este trabalho traz por meio de uma pesquisa de natureza qualitativa, do tipo pesquisaação, a análise do processo de letramento literário em três turmas de $6^{\circ}$ ano de uma escola pública de Curitiba. [...] Foram analisados textos de natureza literária produzidos por alunos-autores, na perspectiva de Ferreiro e Siro, Calkins e Reuter. Para o estudo desses textos, escritos com intenção literária pelos alunos-autores, foram consideradas a escolha de fatores estruturantes: a verossimilhança, a mimese, a expressividade, a lógica e a progressão textual. $O s$ resultados apontam para a eficácia da sequência didática expandida como metodologia para construção e consolidação do letramento literário na escola, para a importância da partilha de leituras entre estudantes como forma de incentivo à formação do leitor. Apontam também que, além do incentivo à criatividade, é necessário ensinar ao aluno-autor modos para explorar a construção do ethos discursivo (grifos nossos).

Neste trabalho, não se nota, como no anterior, uma desqualificação do ensino sistematizado e intencional e nem uma crítica direta aos docentes em atividade. No entanto, chama a atenção: a) que os resultados da pesquisa sejam apresentados em face à lógica de "eficácia" - em consonância, mais uma vez, com o que foi discutido ao longo deste nosso trabalho; e b) que a autora polarize criatividade (como algo a ser incentivado) versus ensino.

Por fim, para demonstrar que as pesquisas contemporâneas nem sempre endossam a perspectiva oficial em relação à criatividade, trazemos o resumo do trabalho de Rangel (2018), intitulado "Entre cigarras e formigas: leituras 
e recepção de Esopo, La Fontaine, Lobato e Manoel Monteiro no ensino fundamental I", defendido na Universidade Federal de Campina Grande (UFCG):

Este trabalho apresenta uma proposta de vivência com a leitura literária no âmbito da sala de aula, tendo como sujeitos alunos do $5^{\mathrm{o}}$ ano do Ensino Fundamental I, através da leitura da clássica fábula A cigarra e a formiga, cuja "origem" é atribuída ao fabulista Esopo, e de versões adaptadas pelos seguintes escritores: La Fontaine (Século XVII), Monteiro Lobato (2010) e Manoel Monteiro (2012). A pesquisa teve como objetivo investigar, por meio da experiência de leitura, a recepção estética das quatro versões, observando aspectos como horizonte de expectativas e repertório de leitura apresentados pelos alunos [...] Os resultados da pesquisa revelaram que, através da experiência de leitura literária desenvolvida, não apenas na sala de aula, mas em outros espaços da escola [...], conseguimos favorecer um envolvimento lúdico quanto à recepção das quatro versões da fábula objeto desse estudo [...]. Verificamos que as estratégias adotadas, por serem sistematizadas, planejadas, prazerosas e pautadas no diálogo e na leitura compartilhada, permitiram o encontro dos leitores com os textos, fato que nos faz acreditar na possibilidade dos mediadores de leitura, que podem realizar um trabalho efetivo e afetivo com a leitura literária na escola, levando as crianças a desenvolverem autonomia, criatividade, imaginação, reflexão e sobretudo, humanização (grifos nossos).

Chama a atenção que os resultados sejam apresentados em relação ao favorecimento do envolvimento lúdico (portanto, do aspecto de brincadeira, fantasia, imaginação) e que haja uma valorização da sistematização, do pla- nejamento e do compartilhamento de leituras, bem como o reconhecimento da atividade dos mediadores de leitura como um trabalho com objetivos claramente definidos. Além disso, cumpre destacar que o estudo de Rangel (2018), mesmo partindo de uma fundamentação teórico-metodológica completamente distinta daquela que expusemos neste ensaio, coloca a criatividade como algo a ser desenvolvido, ao lado de outras funções psicológicas superiores, tais como a autonomia, a imaginação, a reflexão, em suma, a humanização - bem entendida como processo de produção, direta e intencional, em cada ser humano singular da humanidade produzida historicamente e coletivamente pelo conjunto dos homens, como bem nos ensinam, por exemplo, Antonio Candido (1995) e Dermeval Saviani (2003).

\section{Considerações finais}

Em acordo com Saccomani (2014) e Galvão e Saccomani (2019), este trabalho também entende "criatividade" como transformação da realidade por meio da atividade humana, ou seja, considera que a criatividade tem sua gênese no trabalho, e que, nesse sentido, ultrapassa dicotomias presentes em discursos contemporâneos no campo do ensino de literatura e/ou da educação literária (e, assim, da formação de leitores literários). Como exemplos, podemos citar a 
naturalização da oposição entre criação e reprodução, entre construção e transmissão do conhecimento, entre inovação e conservação - e, mais especificamente no que diz respeito às relações entre literatura e educação, podemos recuperar como exemplos a defesa de que a escola deveria abdicar da indicação de obras e textos a serem lidos, do ensino planejado de conhecimentos sistematizados no campo dos Estudos Literários e, enfim, deveria abdicar da avaliação sistemática de leituras e escritas literárias.

Vincados, como as autoras, pela dialética materialista e histórica, entendemos o trabalho como atividade que diferencia humanos e animais e como atividade que, ao mesmo tempo, conserva e transforma a realidade - de modo que a reprodução não seja apenas repetição e conservação, mas igualmente transformação. Assim, defendemos o ensino-aprendizagem de conhecimentos historicamente produzidos e sistematizados pela cultura humana, bem como o estudo orientado dos clássicos literários (na sua dialética com os novos valores postos pelas obras contemporâneas), como modos privilegiados de cultivo e desenvolvimento da criatividade literária dos estudantes em processo de escolarização. Noutras palavras, contrapusemo-nos à defesa da criatividade como um valor inato à criança, que seria "sufocado" pelo processo de educação formal, ou ao entendimento da criatividade como "competência" devota- da à resolução pragmática de problemas da vida contemporânea e imediata.

Reiteramos, assim, o que dissemos no último encontro da Associação Brasileira de Literatura Comparada, realizado em 2018 na Universidade de Uberlândia, quando pontuamos:

É preciso que nos perguntemos: A quem ou a que interessa que não haja um corpo de conhecimentos passível de organização, sistematização, transmissão/instrução, apropriação e objetivação no campo do conhecimento da Literatura? (E que, portanto, seja possível reduzir a formação do professor de literatura a um caldo de informações mal-ajambradas, insistindo em uma suposta formação pela e para a prática esvaziada de adensamento teórico, crítico e historiográfico?) A quem ou que interessa que a Literatura na escola seja reduzida apenas a um momento de deleite, de lazer, de fruição gratuita - ou, noutra feita, ao reino dos equívocos e delírios individuais não como ponto de partida, mas como ponto de chegada? A quem ou a que interessa que os pobres deste país não tenham acesso ao que de mais elaborado a humanidade produziu em termos de conhecimento, procedimento e atitude literárias - debatendo, questionando e transformando esses conhecimentos, procedimentos e atitudes como forma de preparação para uma transformação social mais ampla e de mais radicais proporções?

[...] A redução do ensino de literatura à mera relação sujeito-texto sem qualquer forma de mediação consciente, deliberada, planejada e sistemática prestam um enorme serviço à mutilação da humanidade em cada um de nós e, assim, à reinvenção contínua da roda (ou seja, à negação de que avançamos por superação dialética). Prestam, mesmo, de minha perspectiva, um enorme serviço à perpetuação de uma situação em que os seres humanos não se entendem como participantes de um rico caudal de relações [...]. 
Ou seja, penso que a discussão sobre as práticas de ensino de literatura, no âmbito da comunidade acadêmica (e incluo aqui todos os professores de literatura deste país, sejam os que atuam na educação básica, sejam os que atuam no ensino superior) passa pela desfetichização do ensino de literatura. [...] Questiono o fetiche que se imiscui em posições hoje hegemônicas em nosso campo, que obliteram, desde minha perspectiva, a natureza daquilo que deveria ser a educação literária escolar e, assim, fragilizam a Literatura como campo do conhecimento e como disciplina escolar, esvaziando o trabalho do professor, com consequências nefastas para sua formação, sua carreira e sua prática.

Se não há o que ser ensinado (ou seja, não é necessário transmitir conhecimentos), porque haveria aulas de Literatura? Se qualquer texto vale e se o estudante só precisa conhecer o seu mundo imediato, porque seria necessário haver bibliotecas e centros culturais de qualidade, diversificados, atualizados e com boa curadoria e mediação? Se o trabalho do professor não tem necessidade de selecionar e organizar conteúdos e procedimentos didáticos, de avaliar a aprendizagem, por que ainda se gastaria dinheiro público formando e remunerando pessoas para esse trabalho? Se aquilo que espontaneamente ou no senso-comum sabemos sobre a literatura é tão ou mais legítimo que o saber científico, filosófico e artístico acumulado pelas pesquisas e estudos mais avançados, por que se concederiam licenças e bolsas para a formação continuada dos profissionais da Educação? (DALVI, 2018, [s. p.]).

Finalizando, então, à luz das constatações sobre a reprodução, na BNCC, do ideário afim à atual lógica socioeconômica e produtiva de cariz neoliberal/ ultraliberal e sobre a adesão total ou parcial das pesquisas de pós-graduação à perspectiva oficial em relação à criati- vidade (e, assim, ao projeto de formação humana ensejado a partir da educação literária), parece-me que a citação acima nos convoca como professores e pesquisadores do campo, no momento contemporâneo. Tais me parecem ser os grandes desafios e as grandes questões a serem respondidos pela área, neste momento, no tocante à criatividade no processo escolar e, assim, no processo de humanização dos sujeitos sob nossa responsabilidade profissional - particularmente pela via do trabalho docente com a literatura em contexto escolar.

\section{Creativity in BNCC and in Literary Education researches: inquiries and disclosures}

\section{Abstract}

The treatment of creativity in the school education process is problematized, focusing on the specificities of literary education. The sources for the research were Brazilian official documents, as well as contemporary developed in Brazilian postgraduate programs. What can be seen from the analysis of the official document is the reduction of creativity to an instrumental dimension. On the other hand, the analysis of contemporary research shows the coexistence of different perspectives about creativity in literary education, as well as concerning to importance of literary education in the development of creativity. Thus, the proposal to overcome the belief in creativity as something innate or spontaneous is reposted and, 
in the final part, it is also discussed how the current official perspectives for the teaching of literature in the school can empty both the body of historically produced content about the literature, as well as the specificity of the literature teacher's work.

Keywords: Creativity; Base Nacional Comum Curricular; Literary education; Teaching of literature.

\section{Notas}

1 Uma primeira versão resumida deste trabalho, na forma de recorte parcial e provisório de resultados, foi apresentada como comunicação sob outro título no XVI Congresso Internacional da Abralic, realizado na Universidade de Brasília, em julho de 2019.

2 Esta contextualização está baseada em Saviani (2007) e Frigotto (2010).

3 Nossa crítica à lógica das competências está fundada em Chauí, 2014; Frigotto, 2008; Gentili e Silva, 1995; Mészáros, 2008; Ramos, 2011.

4 Um dos exemplos do tipo de imprecisão teórica/ terminológica em documentos oficiais pode ser visto em Libâneo, 2006. Uma outra análise de apropriação impertinente, que esvazia o contexto e o sentido social da teoria de base, é feita em relação ao pensamento materialista histórico-dialético de Vygotsky, em Duarte (2000).

5 Este assunto é mais extensamente desenvolvido em Dalvi (2019a, 2019b e 2019c).

6 Nossa crítica ao "aprender a aprender" se baseia em Duarte (2000).

7 A articulação que fazemos entre educação escolar universalizada e o desenvolvimento do psiquismo se baseia em Martins (2013).

8 Optamos, neste trabalho, por uniformizar todas as ocorrências do nome Vygotsky e do adjetivo vygotskyana. No entanto, é importante deixar registrado que os diferentes estudiosos de sua obra, bem como as diferentes edições optam por grafias muito distintas entre si.

\section{Referências}

BRASIL. Base Nacional Comum Curricular: educação é a base. Brasília: Ministério da Educação; Conselho Nacional de Secretários de Educação; União Nacional dos Dirigentes Municipais de Educação, 2018. Disponível em: http://basenacionalcomum.mec.gov.br/ images/BNCC_EI_EF_110518_versaofinal_ site.pdf. Acesso em: 15 jul. 2019.

CANDIDO, Antonio. "O direito à literatura". In:_ . Vários Escritos. São Paulo: Duas Cidades, 1995. p. 235-263.

CHAUÍ, Marilena. A ideologia da competência. São Paulo: Fundação Perseu Abramo; Belo Horizonte: Autêntica, 2014.

DALVI, Maria Amélia. Literatura Infantil e Democracia (parte 1). Disponível em: https:// diplomatique.org.br/literatura-infantil-e-democracia-parte-1/. Acesso em: 15 jul. 2019a.

DALVI, Maria Amélia Dalvi. Literatura Infantil e Democracia (parte 2). Disponível em: https://diplomatique.org.br/literatura-infantil-e-democracia-parte-2/. Acesso em: 15 jul. $2019 b$.

DALVI, Maria Amélia. Literatura Infantil e Democracia (parte 3). Disponível em: https:// diplomatique.org.br/literatura-infantil-e-democracia-parte-3/. Acesso em: 15 jul. 2019c.

DALVI, Maria Amélia. Práticas de ensino de literatura. Palestra proferida no XX Encontro da Associação Brasileira de Literatura Comparada. Universidade de Uberlândia (Uberlândia), 2018 [s. p.], mimeo.

DUARTE, Newton. Vygotsky e o "aprender a aprender": críticas às apropriações neoliberais e pós-modernas da teoria vygotskyana. Campinas: Autores Associados, 2000.

DUNKER, Christian. A pós-verdade e seu tempo político. Revista do Instituto Humanitas da Unisinos (online). Disponível em: http://www.ihu.unisinos.br/78-noticias/576912-a-pos-verdade-e-seu-tempo-politico. Acesso em: 25 ago. 2019. 
FERREIRA, Daiane Francis Fernandes. Literatura infantil e pensamento crítico: um estudo sobre contos maravilhosos em livros didáticos da década de 1950 à contemporaneidade. Dissertação (Mestrado em Educação) - Universidade Federal do Espírito Santo, 2018. Disponível em: http://repositorio.ufes.br/bitstream/10/8624/1/tese_12275_ DISSERTA\%C3\%87\%C3\%830\%20DAIANE\%20FRANCIS\%20F.\%20FERREIRA\%20 \%282\%29.pdf. Acesso em: 25 ago. 2019.

FERREIRA, Tainá Soeiro do Nascimento. $O$ conto de fadas na literatura: articulando práticas de leitura no $7^{\circ}$ ano do ensino fundamental. Dissertação (Mestrado em Linguagens e Letramentos) - Universidade Federal do Sul e Sudeste do Pará, 2018. Disponível em: https://sucupira.capes.gov.br/sucupira/ public/consultas/coleta/trabalhoConclusao/ viewTrabalhoConclusao.jsf?popup=true\&id_ trabalho=6375358. Acesso em: 15 jul. 2019.

FRIGOTTO, Gaudêncio. A produtividade da escola "improdutiva": um (re)exame das relações entre educação e estrutura econômico-social capitalista. In: . A produtividade da escola improdutiva. 9. ed. São Paulo: Cortez, 2010 [1989]. p. 151-237.

FRIGOTTO, Gaudêncio (Org.). Educação e crise do trabalho: perspectivas de final de século. 9. Ed. Petrópolis, RJ: Vozes, 2008.

GALVÃO, Ana Carolina; SACCOMANI, Maria Cláudia. A transmissão de conhecimentos como condição para a criatividade: 0 papel diretivo do professor e a criança feliz. Perspectiva [Online], Florianópolis, v. 37, p. 296-315, 2019.

GENTILI, Pablo; SILVA, Tomaz Tadeu (Org.). Neoliberalismo, qualidade total e educação: visões críticas. 3. ed. Petrópolis: Vozes, 1995.

GIROTTO, Eduardo Donizeti. Entre a escola e a universidade: o produtivismo-aplicacionismo na formação de professores em Geografia. 2014. 237 f. Tese (Doutorado em Geografia Humana), Faculdade de Filosofia,
Letras e Ciências Humanas, Universidade de São Paulo.

IBARRA, David. O neoliberalismo na América Latina. Revista de Economia Política (São Paulo), v. 31, n. 2, p. 238-248, jun. 2011. Disponível em: http://www.scielo.br/scielo.php?script $=$ sci_arttext\&pid $=\mathrm{S} 0101$ $-31572011000200004 \& \operatorname{lng}=\mathrm{en} \& \mathrm{nrm}=\mathrm{iso}$. Acesso em: 25 ago. 2019.

LIBÂNEO, José Carlos. Diretrizes curriculares da Pedagogia: imprecisões teóricas e concepção estreita da formação profissional de educadores. Educação \& Sociedade, Campinas, v. 27, n. 96 - Especial, p. 843-876, out. 2006. Disponível em: http://www.scielo.br/ pdf/es/v27n96/a11v2796.pdf. Acesso em: 15 jul. 2019.

LUKÁCS, George. Introdução a uma estética marxista. [s. trad.]. 2. ed. Rio de Janeiro: Civilização Brasileira, 1970.

MARTINS, Lígia Márcia. O desenvolvimento do psiquismo e a educação escolar: contribuições à luz da psicologia histórico-cultural e da pedagogia histórico-crítica. Campinas: Autores Associados, 2013.

MÉSZÁROS, István. A educação para além do capital. [s. trad.]. 2. ed. São Paulo: Boitempo, 2008.

NEVES-PEREIRA, Mônica Souza. Posições conceituais em criatividade. Psicologia em Estudo, Maringá, v. 23, [s. n.], 2018, p. 1-15. Doi: 10.4025/psicolestud.v23.e39223. Disponível em: www.periodicos.uem.br/ojs/index. $\mathrm{php/PsicolEstud/article/view/39223/pdf.}$ Acesso em: 14 jul. 2019.

RAMOS, Marise Nogueira. A pedagogia das competências: autonomia ou adaptação?. São Paulo: Cortez, 2011.

RANGEL, Sandra de Queiroz. Entre cigarras e formigas: leituras e recepção de Esopo, La Fontaine, Lobato e Manoel Monteiro no ensino fundamental I. Dissertação (Mestrado em Linguagem e Ensino) - Universidade Federal de Campina Grande, 2018. Disponível em: https://sucupira.capes.gov.br/sucupira/ 
public/consultas/coleta/trabalhoConclusao/ viewTrabalhoConclusao.jsf?popup=true\&id_ trabalho=7421363. Acesso em: 15 jul. 2019.

SACCOMANI, Maria Cláudia. A criatividade na arte e na educação escolar: uma contribuição à pedagogia histórico-crítica à luz de Georg Lukács e Lev Vygotsky. Dissertação Mestrado em Educação Escolar) - Universidade Estadual Paulista Júlio de Mesquita Filho (Araraquara), 2014.

SAVIANI, Demerval. Pedagogia histórico-crítica. São Paulo: Autores Associados, 2003.

SAVIANI, Demerval. O neoprodutivismo e suas variantes: neo-escolanovismo, neoconstrutivismo, neotecnicismo (1991-2001). In: . História das Ideias Pedagógicas. Campinas: Autores Associados, 2007. p. 423-440.

THIENGO, Lara Carlette; BIANCHETTI, Lucídio; MARI, Cezar Luiz De. Rankings acadêmicos e universidades de classe mundial: relações, desdobramentos e tendências. $E d u$ cação e Sociedade, Campinas, v. 39, n. 145, p. 1041-1058, dez. 2018. Disponível em: http://www.scielo.br/scielo.php?script=sci_ arttext\&pid=S0101-73302018000401041\&ln $\mathrm{g}=$ pt\&nrm=iso. Acesso em: 25 ago. 2019.

VALCANOVER, Camila Augusta. "Trabalha e teima, e lima, e sofre, e sua: letramento literário no ensino fundamental”. Dissertação (Mestrado em Educação: Teoria e Prática de Ensino) - Universidade Federal do Paraná, 2018. Disponível em: https://sucupira.capes.gov.br/sucupira/public/consultas/coleta/ trabalhoConclusao/viewTrabalhoConclusao. jsf?popup=true\&id_trabalho=6734916. Acesso em: 15 jul. 2019.

VYGOTSKY, Lev S. Imaginação e criação na infância. Trad. Zoia Prestes e Elizabeth Tunes. São Paulo: Expressão Popular, 2018.

VYGOTSKY, Lev S. Imaginação e criatividade na infância. Trad. João Pedro Fróis. São Paulo: WMF, 2014.
VYGOTSKY, Lev S. Imaginação e criação na infância. Trad. Zoia Prestes. São Paulo: Ática, 2009.

VYGOTSKY, Lev S.; LURIA, Alexander R.; LEONTIEV, Alexis N. Linguagem, desenvolvimento e aprendizagem. Trad. Maria da Penha Villa-Lobos 10. ed. São Paulo: Ícone, 2006.

VYGOTSKY, Lev S. Pensamento e Linguagem. Trad. Jefferson Camargo; José Cipolla Neto. São Paulo: Martins Fontes, 2000. 